\title{
Customized L2 e-courses as a Shortcut to Developing Learner Autonomy and Lingua-Professional Competences of Students Majoring in Finance and Law
}

\author{
Elena Gavrilova \\ Kira Trostina \\ Dinara Tutaeva \\ Plekhanov Russian University of Economics, Russia
}

Lilit Sahakyan

Yerevan Gladzor University, Armenia

Doi:10.19044/esj.2019.v15n13p301 URL:http://dx.doi.org/10.19044/esj.2019.v15n13p301

\begin{abstract}
Senior Bachelor and Master Students in economic and law universities view English for Special Purposes (ESP) course as an essential component in developing both their linguistic and vocational competences. The paper argues that reliance on the use of e-shaped professionally-relevant materials is a shortcut to professional jargon acquisition and pre-employment immersion into future job realities. The existing shortage of published ESP textbooks for students of finance and law stipulates the necessity for the teachers to develop their own customized courses tailored for particular students' needs. Embracing the opportunities provided by information technologies and custom-built e-courses composed of autonomous e-modules has helped to create a personalized virtual learning environment for ESP students of any learning profile or academic background. In addition, it has helped in responding to the challenging contemporary labor market demands.

The paper hypothesizes the paramount importance of converting selected study materials into an interactive electronic format in order to better equip students of finance and law with linguistic and professional skills. A questionnaire related to the students' perceptions on the e-course relevance on 5-point Likert-type scale was administered to 208 bachelor and master undergraduates in Finance. This was administered after the pilot introduction of a configurable e-course at the Faculty of Distance Education in Plekhanov Russian University of Economics (PRUE), Moscow, Russia. Thus, it was also administered to 67 bachelor and master students of law and finance of Yerevan Gladzor University (YGU), Armenia. The survey concludes that tailored e-
\end{abstract}


training courses get a massive student support and serve as a springboard for boosting students' lingua-professional development and enhancing learner autonomy. However, the findings also revealed that the participants of the study even in geographically remote universities, who have quite different cultural and multicultural specificities and prefer working with the printed out paper-based version of the interactive courses, significantly outnumber $(83 \%)$ those who rely solely on e-learning format (34\%). The results of the study are critical to e-courses developers, university IT and administrative staff, and it also provide trajectories for further research.

Keywords: interactive course, EPP, tertiary e-education, foreign languages, student autonomy, PRUE, YGU

\section{Introduction}

Student autonomy in foreign language (L2) studies has sprung on the agenda of higher education as a response to dramatic curricula changes (decreased number of classroom hours), big heterogeneous groups, and sporadic students' free attendance. However, it should be emphasized that for a number of language teachers, regular attendance as a classical course requirement and policy is considered to be the cornerstone of EPP courses that are tailored to meet the needs of those studying or mastering in field-specific areas in English. Hence, this is primarily aimed at optimizing the target learners' effectiveness in using professional English and attaining the required skills, abilities, and knowledge that are thought to be of vital and indispensable importance for L2 learners majoring in domain-specific areas. Notably though, having to combine their academic studies and work in the conditions of permanent time constraints, students have to earn the scheduled number of credits to pass exams and get their diploma. Thus, the traditional teachercentered educational system, which extensively utilizes conventional methods of teaching, no longer meets the demands of the generation $\mathrm{Z}$ students whoopt due to more autonomy in their educational opportunities and flexible approach.

The notion of learner autonomy rests on the idea that the higher the students' involvement in decision making process regarding their own knowledge acquisition, the more enthusiastic about learning they are likely to be (Little, 2004). Therefore, students need to be encouraged to develop their own strategies in learning a foreign language. There is a significant shift in the language teachers' role in an autonomy-oriented classroom as they play a crucial role in fostering students' autonomy in both classroom and out-of-class settings. Language teachers themselves are expected to create the learning culture where autonomy and ingenuity are praised. Discussing the relationships between technical and pedagogical interactivity, they have a 
greater focus on learning goals during activity in order to enable learners to be more autonomous in exploiting ICT's affordances. Brandl (2002) made an observation that the design of an Internet-based lesson is largely determined by a teacher's pedagogical approach, her/his technological expertise, and the students' language proficiency with a notable shift in approaches of integration of internet-based reading materials into the foreign language curriculum from teacher-determined or teacher-facilitated to student-centered. So, when composing their classes, they must take into account various possibilities which digitization of higher education can offer them. And last but not least, they have to provide their students with curricula roadmaps with the clearly-marked milestones for their self-study drives.

In contemporary universities, a relatively short elective or core course of English for Specific Purposes (ESP) for the bachelor and master students of Finance and Law provides sufficient opportunities for students' autonomy due to several reasons. Firstly, the groups' age and linguistic heterogeneity, together with cultural diversity and irregular attendance, make these groups very difficult to handle and help to keep learners motivated. More than that, the scarcity of available textbooks creates even more serious challenge for the ESP teacher. Those present on the market of educational literature mainly follow 'one size fits all' approach and the number of narrow specialized textbooks is second to none. Finally, despite the abundance of open-access supplementary materials and the fact that the academic world is becoming more and more technologically inclined and proficient, teachers are often still unaware about how to use e-resources to their best advantage. In investigating English as a foreign language (EFL) teachers' use of Internet assistive technologies, Celik (2013) reveals that although EFL instructors utilize the Internet densely and with a positive perception in their teaching, the quality of that utilization varies and needs to be improved via professional development programs for Internet-assisted language instruction. Therefore, to address the professional communication students' needs and maintain their interest on the subject, the ESP teachers have to customize each course and accessorize learning activities with digitized sub-curricular components such as interactive workbooks or electronic education complexes which enhances the autonomy constituent to motivate the learners to dig deeper into the subject. Developing such teaching materials for tertiary education with the emphasis on the professional component, such as Accountancy, Taxation, International Law, etc. finds its outcome in creating e-training educational modules in English for Specific Purposes. Such projects are aimed at both training students in their particular area of specialization in English, and equipping them with abundant autonomous workload, letting them not only to acquire professional jargon but to also collect academic credits as well. 
Professional studies in finance and law have also witnessed the shift to autonomous learning supported by the technological breakthrough. Kurt (2015) prioritizes the necessity of designing courses using distance education and also highlights the utmost importance of teachers' abilities and skills to fully understand the "three technological configurations available - additive, integrated, and independent". Accordingly, teachers need to make their efforts to keep up with new software and hardware, and they are to learn how to utilize those instructional materials and tools appropriately and how to incorporate and integrate them into their teaching to efficiently create effective learning environment and to best meet target learners' needs thus reaching the primary goal of improving education. Consequently, teachers need to know how to modify their teaching and learning methods in order to provide students with the key of becoming more independent learners and promoting autonomy and life-long learning through educational technology.

For example, Belias et al. (2013) necessitated this by using both traditional teaching methods as well as "teaching through the application of information" and "communication technologies in the accounting field". Sithole (2015) sees the accounting profession as one of the most demanded and at the same time demanding in the field of economics with a wide range of various skills required by employers. Bashir (2000) emphasizes the importance of open learning in accounting with its focus on flexibility, user choice, and learner autonomy which helps to develop important personal and business skills, encourages learner involvement, and personalizes education.

According to Supardi (2016), EFL learners can have sufficient mastery of Legal English vocabulary, and it is important for the EFL teachers to be creative and innovative in facilitating their autonomy in mastering LE vocabulary. Additionally, Đorđević and Radić-Bojanić (2014) stated that to increase the level of students' autonomy in the implementation of digital resources for Legal English writing, teachers need quite a long time to cultivate their competences to use digital resources purposely. Also, they should apply a structured method from the very beginning of tertiary education, so as to help students to grasp the overall picture of how to research sources autonomously, how to select the right ones independently and critically, and how finally to successfully incorporate their findings into their ESP production.

Giving students a range of choices in the areas of course content, methods of study, and modes and timing of assessment results in more effective student learning.

\section{Data and Methodology}

This study was a desk research of theoretical literature and empirical studies on the topic of customized e-courses in ESP studies. The literature 
surveyed included scientific periodicals, global and national corporations' websites and posts by working financial and law professionals, and available course books in Professional English in Finance and Law. The aim of this approach was to highlight the modern trends in e-course development and to pinpoint the issues of concern for the EFL e-product contributors. The overview of professionally biased websites provided the insight into the core skills and competences prerequisite for the graduates in Finance and Law to find employment. The obtainable electronic and paper-based study literature for Financial and Law English courses was analyzed to identify the contents and structure requirements.

The field research adopted a cross-sectional survey approach to collect and analyze the feedback of the participants of the study's (ESP teachers and students) perceptions of the role of interactive e-courses in a professional foreign language.

The study population comprised 208 students, i.e. four groups of BA students of Accounting and six groups of MA students of Finance at the Faculty of Distance Learning at Plekhanov Russian University of Economics, Russia, in 2016-2018 academic years. On the other hand, it also comprises of 2 groups of BA and MA students majoring in Jurisprudence and 2 groups of BA and MA students majoring in Finance at Yerevan Gladzor University. The objectives was to assess the students' perspectives on increasing learner autonomy via wide implementation of interactive professionally-oriented language e-courses, identify the possible constraints and provide guidelines for further course improvements, and fostering student autonomy. The survey aimed to collect and statistically summarize students' visions as to what extent they are satisfied with the interactive approach to ESP classroom management and notable shift in their learning autonomy.

Brainstorming sessions with the 9 ESP teachers practicing in the undergraduate courses in PRUE were conducted. Here, open-ended questions were discussed in order to obtain data on their general understanding of student autonomy, interactive approach to ESP teaching, and special emphasis on the L2 teachers' role in developing not only linguistic but professional competencies as well.

The key research questions addressed were:

- How can interactive e-courses enhance students' autonomy?

- What are the students' perceptions about their relevance to their linguistic and professional competences development?

- How does the teacher's role change in an autonomy-oriented ESP classroom? 


\section{Discussion}

English for Specific Purposes course is a relatively short elective course $(36+32$ classroom hours in the year the research started (2016), currently being constrained to $28+28)$ in PRUE and a core course $(32+32$ for BA students and $32+32+32$ for MA students) in YGU. Thus, this is delivered to heterogeneous academic groups that sample great age, linguistic and academic abilities diversity as shown in Diagram 1.

Despite these differences, students generally have high expectations from the course as they directly link its content with their future career prospects and employability. Hence, the ESP teachers may take advantage of the students' interest and enthusiasm to their course and thus maximize its learning potential. On the other hand, though, there is a notable problem with the specific study content for the ESP courses unlike the existing abundance of high-quality both printed and on-line study materials from international publishing houses on General and Business English, the choice of textbooks for professional language acquisition is very limited in the educational market. Conversely, the textbooks for professional linguistic courses are too generalized, are not ranged according to the linguistic level of students (which, according to data obtained in our research, may range from low-intermediate to advanced), and do not fully respond to the Finance and Law students' demands. The situation is even more complicated by irregular students' attendance as many of them work part- or even full-time. Thus, to cover the existing inherent gaps, ESP teachers have to create their own study materials and customize them to the particular student group.

Diagram 1. Heterogeneity of academic groups

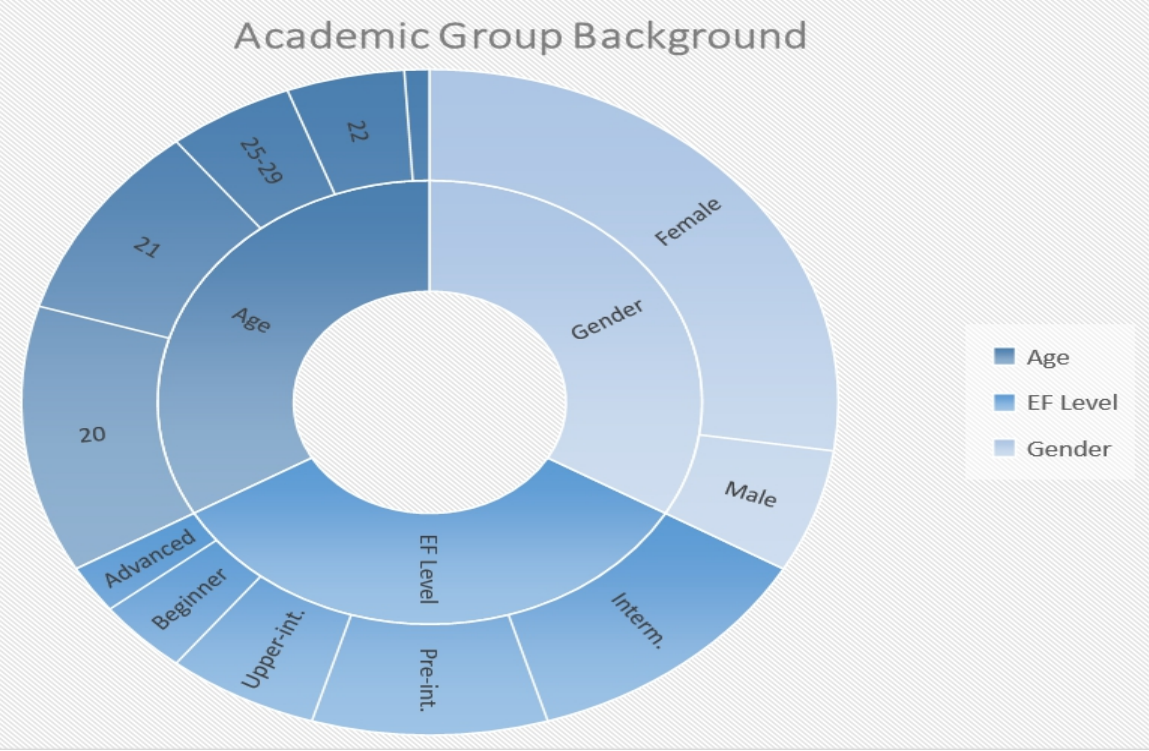


As far as the specifics of teaching ESP for the finance and accounting students in Russian Economic Universities is concerned, there is another additional encumbrance: Russian accounting system is based on the national GAAP, whereas Armenia uses IFRS. This results in students' incomprehensibility of some aspects, unusual textbook structure, and the way of studied material delivery in case of PRUE. Nevertheless, many finance and accounting graduates seek employment with the Big 4 or other multinational corporations where they are expected to demonstrate the knowledge of IFRS principles as well as a good command of both general and professional English. For example, all available vacancies in the official site of Price WaterhouseCoopers (PWC) in Russia are given in English (see Appendix, Figure 1), and the required linguistic level for particular vacancies is upperintermediate (see Appendix, Figure 2).

As to the specifics of teaching ESP for law students at Yerevan Gladzor University, it should be highlighted that teaching Legal English is a challenging task, but it is feasible for a competent ESP teacher. Legal English course designed for BA senior students and MA students majoring in Jurisprudence at YGU initially focuses on accurate usage of the legal vocabulary and style, language range and structures, thus aiming at teaching students professional legal English in the manner that students can apply the obtained skills of legal English and developed field-specific competences not only to meet academic requirements of the BA or MA degree programs but also afterwards implement them in their authentic domains. For YGU ESP teachers, it is of utmost significance to find the most appropriate pedagogical methods, approaches, and techniques to facilitate students' language acquisition, concept understanding, and cultural awareness. The content and methods of teaching Legal English is attentively modified to cover the four language skills and provide cross-cultural comparison and contrast of the Armenian legal system, court structure or other relevant legal subjects and American, British or European legal cultures. However, the burden of ESP teachers at YGU sometimes is tougher. In cases of MA students majoring in Law, many of them have no legal background education, and it is challenging for the teacher to teach Legal English to MA students who have BA degree in Philology, Arts, History or Physical Education. Therefore, the expertise of the ESP teacher as a mentor and a skillful linguist, for having a motivated ESP learner and later a competent specialist knowing English for Law, is of ultimate importance.

To better tune their study programs and content to current job market demands, some universities have attempted to implement Content and Language Integrated Learning (CLIL) programs which may most perfectly meet contemporary students' educational needs. However, wide integration of these programs is restrained by several considerations. Generally, subject- 
matter lecturers are not proficient enough to deliver lectures and conduct seminars in domain-specific English professionally. Let alone, those ones with fluent professional English usually have a lot of tempting highly-paid job offers and are present in universities mostly as guest lecturers and consultants. Conversely, foreign language teachers have no finance or law educational background or working experience and are unqualified to deliver lectures in accountancy, finance or law. Following other issues in implementing CLIL non-English speaking universities (Gavrilova \& Trostina, 2014), ESP becomes the only option available to Finance and Law students to master their professional jargon.

ESP courses in finance and law are extremely challenging for L 2 teachers who have to go beyond their comfort zone and plunge themselves into lexically and professionally uncharted activities. Bracaj (2014) stated that ESP teachers should be additionally trained so that they can be professionals and well-prepared to meet learners' needs. Even more so, tailor-made courses not only demand much more preparation time on the teachers' side including learning a very specific block of vocabulary and finding their definitions and explanations, but they require the content selection plus its methodical processing (drafting various types of exercises, questions, role-plays, etc.) as well. Besides, senior bachelor and master students are undoubtedly more knowledgeable in their subject-matter than L2 teachers which may put the latter in an awkward situation of financial illiteracy. And last, but not least, as any successive course in the language studies must offer something new and challenging for the students, the teacher is expected to create conditions where the sensation of further advancement in a foreign language is maintained. Unsurprisingly, ESP teachers always have to be on the lookout for new and better ways of their course optimization and learning outcomes maximization. In this connection, it seems reasonable to make emphasis on student autonomy and navigate students along both main and minor roads where they can make personal intellectual detours to the areas of their narrow professional interests.

The best scenario to meet the course formal requirements, future employers' expectations and students' educational needs seems to be accessorizing ESP curriculum with interactive e-courses with focus on student autonomy in knowledge acquisition and information search, self-study, and self-control. Our pilot projects in two groups in launching interactive ecourses in accountancy in PRUE in 2016-2017 academic year, succeeded by further e-modules development catered for the 2017-2018 academic year students and in four small groups being launched interactively for the target audience between 2016-2018 academic years in YGU, have revealed the following major advantages of basing the study process on them in comparison with traditional teacher-directed and teacher-controlled classroom management. 
- $\quad$ E-content is flexible and easily customized for a particular course. Depending on the curricula or students' needs analysis, the e-modules and test sections are either closed or disclosed to tailor a specific course.

- $\quad$ E-studies produce a synergetic effect as they develop both linguistic and professional competences. In line with containing a rich glossary of professional vocabulary and lots of self-study exercises, e-courses provide a lot of links to open-access on-line resources such as sites of professional organizations, specialized journals or various study materials by the best scholars in the field.

- $\quad$ E-modules can be built up as inexhaustible e-resources, where the links to current articles, videos and podcasts are added or updated, discussion boards and chats are launched.

- $\quad$ E-courses provoke critical thinking and enhance students' autonomy. One of the most important aspects of self-learning is getting accurate feedback for the progress. Each block of an interactive e-course is usually supplied with review questions, completed with feedback and detailed explanations. A selfcheck 'Test yourself' section after each topic enables students to learn from their mistakes. When students finish a major topic, they are offered to do a quiz, for which they get a grade. That way they can be sure that they have a real understanding of the course's topics and have mastered all topic vocabulary. These observations support Bañados (2006) view that some of the core concepts underlying its design focusing on the importance of creating interactive multimedia environment for authentic communication are multimodal L2 input exposure, enhanced input, learner-fit content delivery, interaction (human-computer, human-human, and intrapersonal) through computer supported collaborative and individual learning tasks, as well as a more human-like dimension for positive and corrective feedback.

The study used a questionnaire survey, premeditated to gather the students' views on such areas as the relevance of the e-course for their future job experiences, the sufficiency of home tasks for autonomous search, the applicability and ease of use of the self-control testing system, the timings for particular tasks, etc. Diagrams 2 and 3 summarize the statistics elicited from the questionnaires on students' perceptions of the linguistic and professional relevance of the various aspects of the interactive ESP modules. 


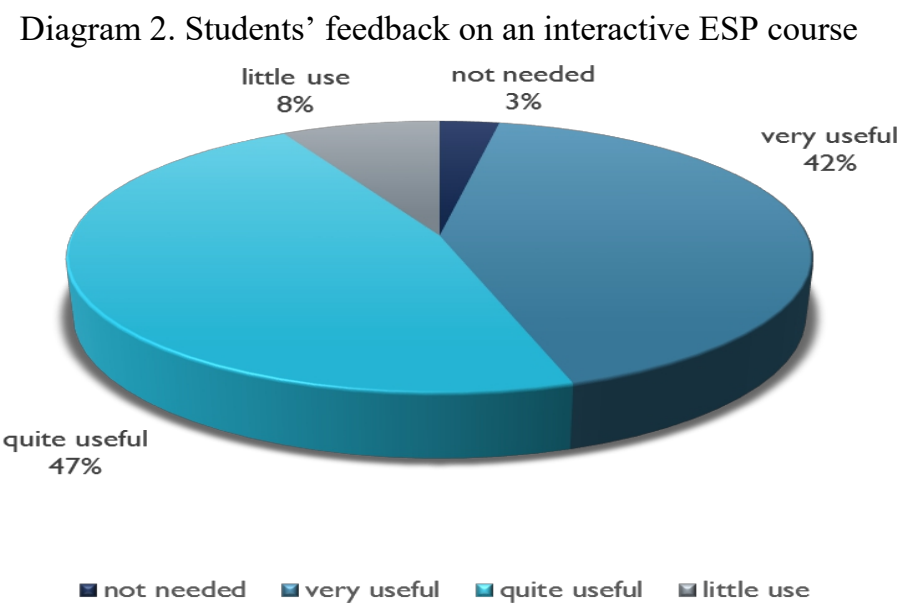

The data from the pie chart shows that more than $2 / 5$ (42\%) of all students find the e-course very useful. This is together with $47 \%$ of those who consider it to be quite useful on account of the overwhelming majority of satisfied students. On the other hand, some $11 \%$ of surveyed students see little or no use of the interactive ESP course for their studies and future work. As a matter of fact, 3 out of 4 students being full-time employed are faced with irregular classroom attendance. Therefore, the opportunity of learning the subject distantly in a self-time-management mode is valued highly.

Diagram 3. Students' feedback on interactive constituents of an ESP course

What attracts students?

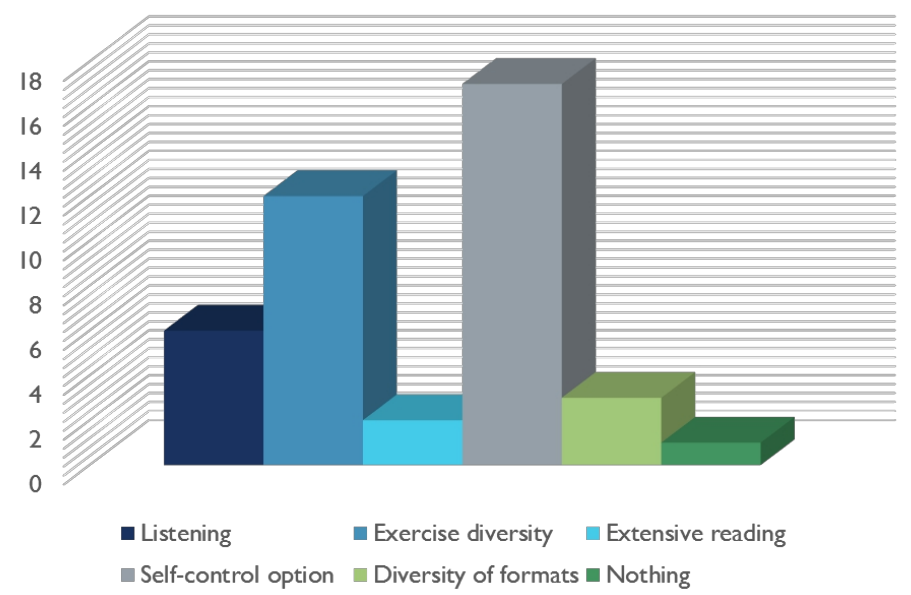

As far as the particular activities in an e-course are concerned, the results presented in the diagram prove that the most valued option is the possibility of self-control which is one of the most important aspects in student autonomy. Another notable option which finds enthusiastic students' support is the 
exercise diversity which, together with the diversity of formats, is almost as valued as the self-control option. Extensive reading is the least popular learning activity which may be explained by the chronic lack of time of the working students or the intentional unwillingness of the modern students to approach lengthy information blocks of many paragraphs.

What most students admitted after-course was that they highly appreciated their involvement in the project. Their feedback being screened and recommendations being taken into account helped the authors not only to improve the subsequent e-modules, but it also resulted in the overall healthier group performance in both language studies and accountancy seminars. Upon the completion of the first semester course, the students claimed that if they had to deal with the financial statements in English, they would rather feel comfortable about them (50\% claimed they would mostly understand; $39 \%$ would understand partially; while $5 \%$ and $6 \%$ would understand respectively everything or nothing, which is directly correlated with their course entrance EF level).

Diagram 4. Students' feedback on the further ESP e-course development

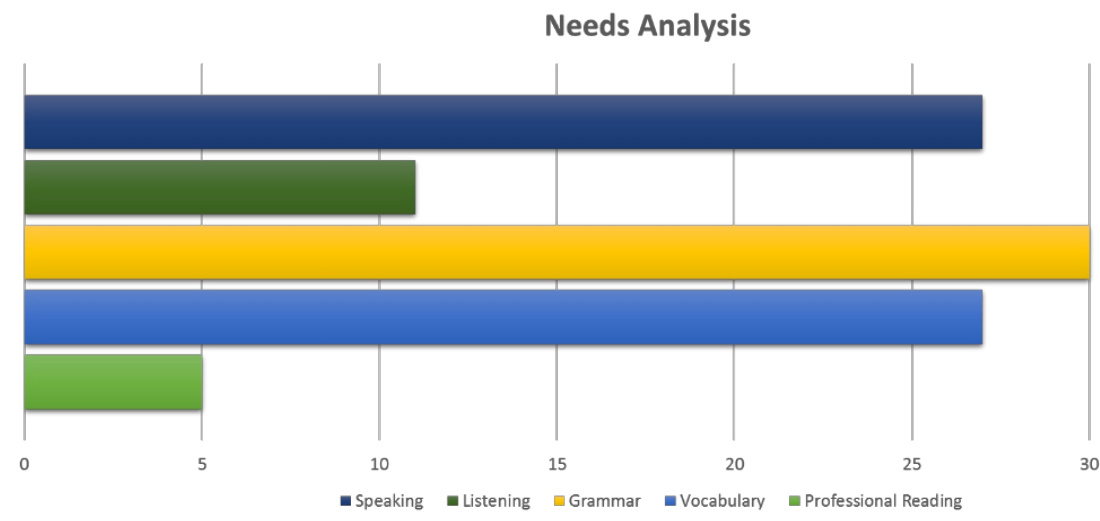

Upon a semester of studies, the students were asked to contribute to the pilot e-modules by submitting their proposals on what sections of the course they would like to have enhanced. As illustrated in Diagram 4, the majority of the students felt that speaking and vocabulary sections should be expanded. Contrary to the course developers' expectations, the largest request was to increase the grammar section, whereas the amount of listening exercises was considered to be sufficed. The students showed little interest in the extension of professional reading which could somehow be explained by their employment statuses (23\% being unemployed, 53\% employed in their future degree field, $24 \%$ employed outside of their future degree field - meaning roughly half of the group have enough reading practice at their workplace, while the other half do not yet realize what kind of literature they will have to read when employed as accountants). 


\section{Controversies}

Despite the proven advantages of e-courses for the optimization of the ESP teaching, there are some areas of controversy as well. Primarily, creating customized e-study content is very time-consuming and laborious for the course developers. As these teachers' drives are rarely adequately compensated, their enthusiasm may finally fade. Much depends on the institution of higher education where they work. If the interim and final course results are monitored and if necessary the project is supported by the department heads and administration, there is more chance that such courses will continue to develop and even become commercially profitable since the best of them may be patented and sold to other universities.

Another danger of drawing up own e-courses lies on the possibility of the copyright infringement as ESP teachers often find the content on the Internet sites where some of the materials are in open access whereas others may be protected by the intellectual property laws. Principally, as L 2 teachers are not qualified enough in the subject-matter to write their own texts on various aspects of their students' profession, the choice of such materials must be done with great caution. All e-materials to be selected for the e-course have to be taken from open-access e-sources and undergo a thorough adaptation and plagiarism testing, no teacher risking to be accused of illegal use of someone else's work.

Moreover, selecting, processing, and customizing study content for ecourses is not enough as it should be converted into an electronic format which in turn requires close collaboration with the IT support department. However, the fact that the licensed software used in a university may be single-formatted or insufficient for the e-course means that the content-developers, targeting more competences to cover thus opting for more diversity in the e-product, will have to outsource IT-specialists, which may be rather costly.

Significantly, that contrary to pre-introduction phase expectations, the survey revealed that provided the students are offered a choice between solely interactive and paper-based versions of the lingua-professionally customized course-books, the majority (83\%) would opt for the paper copy to be studied in the classroom (see Diagram 5). On the other hand, the breakdown of preferences in terms of electronic study material is almost balanced and to the larger extent correlated with the employment status of a learner (34\%). These conclusions are supported by Yamson et al. (2018) research results which indicate that the majority $(57 \%)$ of the respondents always preferred print resources for their academic work. 
Diagram 5. Students' preferences in the study material submission Students' preferences

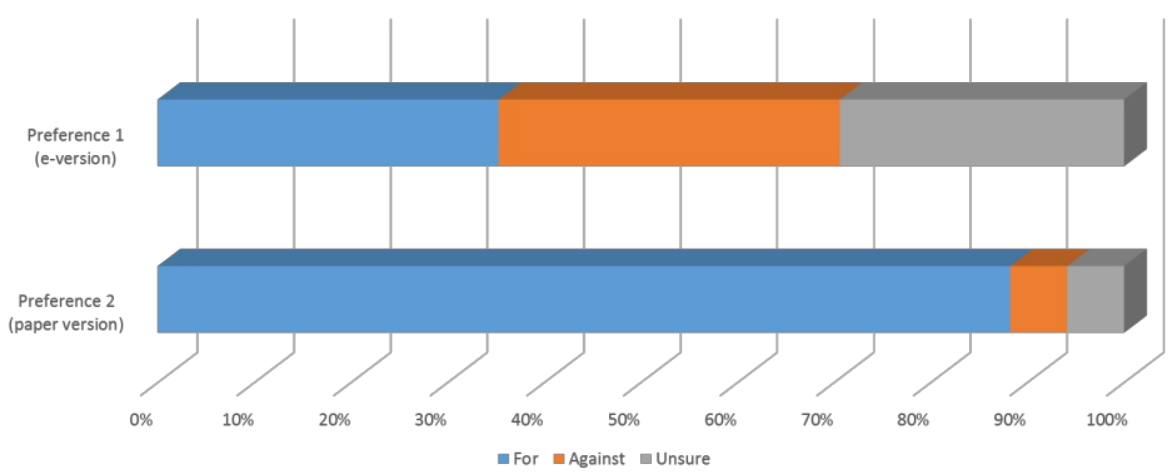

Analysis of the students' comments reveals that from the learner's point of view, one of the major drawbacks of digitalized study materials is the difficulty or impossibility of making notes from them. This research result supports the findings of Chun and Plass (2000) who pointed out that "the use of networked environment for learning in general, and for second language acquisition in particular, raises many questions regarding the design of these environments that differ from the traditional design of text-based and standalone systems".

In addition, some other drawbacks of using e-materials are linked mostly to the use of digital devices themselves. As the learner device has limited battery life, it has to be regularly charged. The student's gadget may have technical problems limiting the access to e-learning materials. Furthermore, some students complain of eye strain after working with screened texts or doing e-exercises/tests for a long time.

\section{Conclusion}

Interactive customized e-courses in various fields of finance and law are an effective way to give students' language studies the boost that they need. The synergy of traditional methods and new educational technologies makes the learning process student-centered, improves the quality, and prepares university graduates for their future professional activities.

Interactive e-courses are able to take into account various nuances of students' linguistic abilities and can provide a lot more study materials than printed textbooks. However, most importantly, they can intensify students' self-engagement in search of professionally-relevant information and knowledge and thus serve as a catalyst for maximizing learning and increasing students' autonomy.

The trend of applying e-learning as a learning and teaching tool has rapidly expanded into higher education. Technologies have dramatically changed the 
way people gather information, carry out research, and communicate with others. Fast-developing technology, which is now being increasingly used in instruction to improve teaching and learning, has removed the distance obstacles and has made it possible for higher education to effectively teach anyone in any geographical location. This rapid development of technology integration has presented a better pattern to find the new teaching models. Consequently, it has a key role in learning and teaching language skills with great emphasis on student autonomy and self-study. Thus, current trends indicate that this will necessitate broadening our understanding of learner autonomy and its role in the complex learning and technology nexus.

Reviewing the issues related to technology integration in the learning and teaching of language skills has elaborated teachers' roles and learners' roles. Gilakjani (2017) makes a conclusion that the integration of technology into the classrooms considerably improves the learning and teaching of English language skills. Our findings suggest that interactive customized educational material becomes the catalyst for increased students' autonomy and linguaprofessional progression and students mainly prefer personalized teachercentered methods to conventional ones. However, contributing to the research on learner autonomy, Collentine (2011) suggests that learners' linguistic complexity and accuracy while completing CALL-based (Computer-Assisted Language Learning) tasks is influenced by both their autonomous moves and the linguistic complexity and accuracy of the input they receive (as a result of their autonomous moves). Thus, it is recommended that if the aforementioned tailored e-courses be used as key learning tools, it must be done under the controlled teacher guidance and support. These findings have obvious implications for the design of ESP course curricula by professional bodies and/or Higher Education Institutions in order to help graduates meet and adapt to the demands for professional competency development in the future graduates professional fields.

\section{References}

1. Bashir, T.H. (2000). Accounting instruction using the open learning approach. Journal of Accounting Education. Volume 18, Issue 3, Summer 2000, Pages 229-240. https://doi.org/10.1016/S07485751(00)00015-4.

2. Belias, D., Sdrolias, L., Kakkos, N., Koutiva, M., \& Koustelios, A. (2013). Traditional teaching methods vs teaching through the application of information and communication technologies in the accounting field: Quo Vadis? European Scientific Journal. Vol 9, No 28 (2013): ESJ October Edition.

3. Bracaj, M. (2014). Teaching English for Specific Purposes and Teacher Training. European Scientific Journal. Vol 10, No 2 (2014): 
ESJ

January

Edition,

DOI: http://dx.doi.org/10.19044/esj.2014.v10n2p\%25p

4. Brandl, K. (2002). The integration of internet-based reading materials into the foreign language curriculum: from teacher-to student-centered approaches.

5. Celik, S. (2013). Internet-assisted technologies for English language teaching in Turkish universities. Computer Assisted Language Learning, 26(5), 468-483.

6. Chun, D.M. \& Plass, J.L.(2000). Networked multimedia environments for second language acquisition. Network-based language teaching: Concepts and practice, 151-170.

7. Collentine, K. (2011). Learner autonomy in a task-based 3D world and production.

8. Đorđević, J. \& Radić-Bojanić, B. (2014). Autonomy in the use of digital resources in a Legal English course. Journal of ESP for Tertiary Level, Vol. 2(1)(2014): 71-87. Retrieved from: https://www.esptodayjournal.org/pdf/vol_2_1/4.DJORDJEVIC\%20\& \%20RADIC-BOJANIC\%20-\%20full\%20text.pdf

9. Fang, Y. (2010). Perceptions of the computer-assisted writing program among EFL college learners. Journal of Educational Technology \& Society, 13(3), 246.

10. Gavrilova, E. \& Trostina, K. (2014). Teaching English for Professional Purposes (EPP) vs Content and Language Integrated Learning (CLIL): the case of Plekhanov Russian University of Economics (PRUE). European Scientific Journal, ESJ, 10(10).

11. Gilakjani, A. P. (2017). A Review of the Literature on the Integration of Technology into the Learning and Teaching of English Language Skills. International Journal of English Linguistics, 7(5), 95.

12. Kurt, S. (2015). "Educational Technology: An Overview," in Educational Technology, November 18. Retrieved from https://educationaltechnology.net/educational-technology-anoverview/.

13. Little, D. (2004). Constructing a theory of learner autonomy: some steps along the way. Centre for Language and Communication Studies. Trinity College Dublin. Retrieved from: https://www.researchgate.net/publication/252532772_Constructing_a _theory_of_learner_autonomy_Some_steps_along_the_way

14. Sithole, S.T.M. (2015). Quality in accounting graduates: employer expectations of the graduate skills in the bachelor of accounting degree. Vol 11, No 22 (2015): ESJ August Edition

15. Supardi (2016). Using Qizlet for facilitating the learner autonomy in mastering Legal English vocabulary. The Third International 
Language and Language Teaching Conference (ILLTC 2016), At Sanata Dharma University, Yogyakarta, Vol.: First Ed. Retrieved from:

https://www.researchgate.net/publication/312728140_USING_QUIZ LET_FOR_FACILITATING_THE_LEARNER_AUTONOMY_IN_ MASTERING_LEGAL_ENGLISH_VOCABULARY

16. Supardi (2015). English for specific purpose: teaching legal english to law students via e-learning. The 62nd TEFLIN International Conference. Retrieved from:https://www.researchgate.net/publication/301593351_ENGLIS H_FOR_SPECIFIC_PURPOSE_TEACHING_LEGAL_ENGLISH TO_LAW_STUDENTS_VIA_E-LEARNING

17. Yamson, G.C., Appiah, A.B., \& Tsegah, M. (2018). Electronic vs. Print Resources: A Survey of Perception, Usage and Preferences Among Central University Undergraduate Students.European Scientific Journal. Vol 14, No 7, pp. 291-304. DOI: http://dx.doi.org/10.19044/esj.2018.v14n7p291

\section{Appendix}

Figure 1. Sample PWC vacancies for Russia

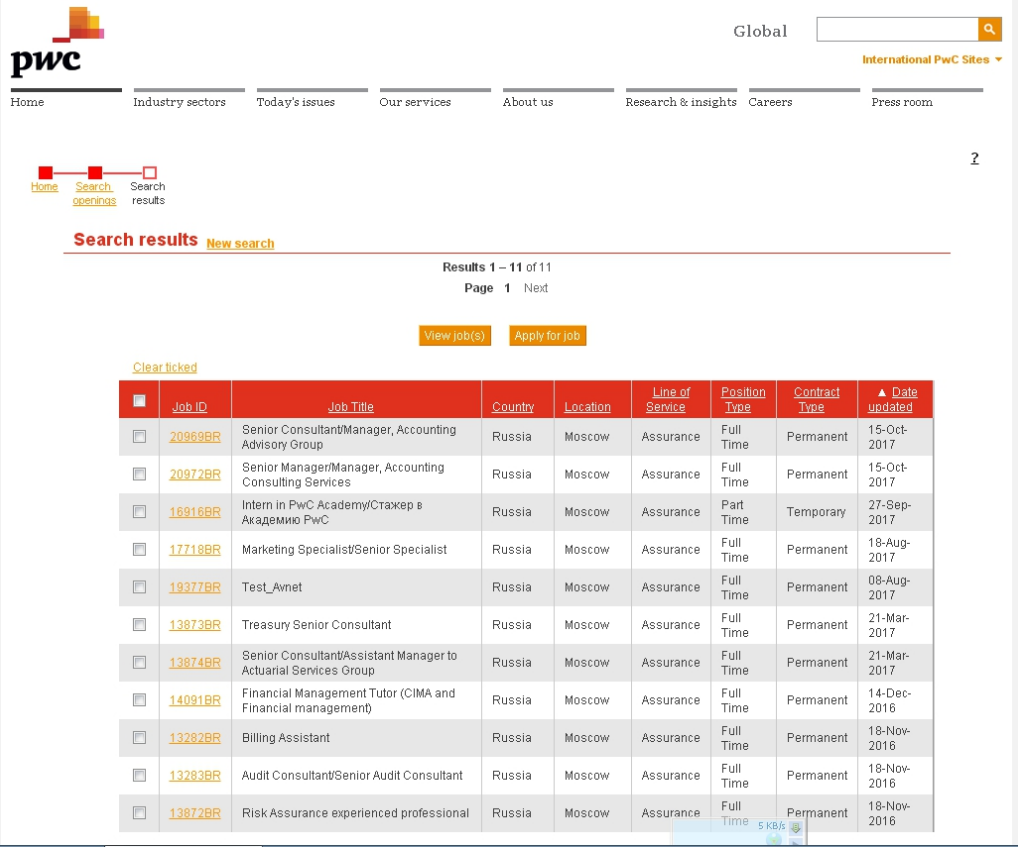

Source: Retrieved from: https://krb-

sjobs.brassring.com/tgwebhost/searchresults.aspx ?PartnerId=30056\&SiteId=6435\&Function $=$ LinkQuery\&LinkId=1497 (Accessed on 20.10.2017) 
Figure 2. Sample required linguistic level for a vacancy in Russia

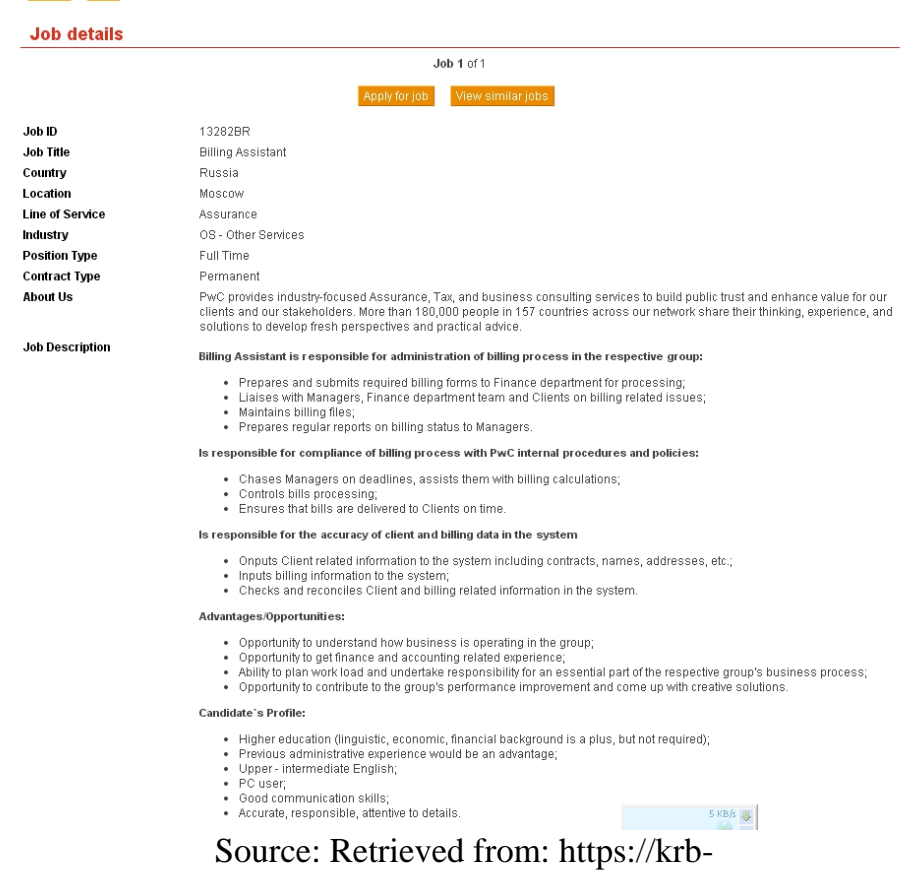

sjobs.brassring.com/tgwebhost/jobdetails.aspx?SID=\%5esTpUdOsLeHmOM0ER\%2fa58U4 qJd8XRlfALLhIo3duJmlr9PIBeU_slp_rhc_zdbY\%2fUCB7UKTqb\&jobId=985602\&type=s earch\&JobReqLang=140\&recordstart=1\&JobSiteId=6435\&JobSiteInfo=985602_6435\&GQ $\mathrm{Id}=4150$ (Accessed on 15.10.2017) 